To Cite: Arora, P. (2006). Karaoke for Social and Cultural Change Production of Novel Educational Content for Information and Communication Technologies in Rural India. Information, Communication \& Ethics in Society, 3: 121-130

\author{
Karaoke for Social and Cultural Change \\ Production of Novel Educational Content for Information and Communication Technologies in \\ Rural India \\ Payal Arora \\ Columbia University, New York \\ pa2177@columbia.edu
}

\begin{abstract}
This account demonstrates the key challenges faced in producing engaging educational content for information and communication technologies (ICT) deployed in rural India. The "Stills in Sync" (SIS) project aims to enhance literacy through the revival and proliferation of popular regional folksongs with social awareness themes in rural India. This product entails the use of the Same Language Subtitling (SLS) karaoke feature that won the Worldbank Development Marketplace award in 2002 and the 'Tech Laureate' honor from the Technology Museum of Innovation in 2003. This case study highlights the struggles faced in the production process as we sought to negotiate localism with scalability. The paper is meant to stimulate discussion and further research on the process of digitalizing cultural and educational content in muliple languages for literacy gains and empowerment. I attempt to give three-dimensionality to current buzzwords in education content creation using ICT: localism, relevance and engagement.
\end{abstract}

Key Words: folksongs, literacy, technology, language, engagement, localism, India

I Building Context 


\section{Education in India}

Prior to 1996, Indian education policy focused more on equity through access, making some significant strides. By 1987, the Indian government had set up 530,000 primary schools, providing access to 95 percent of the young population across 80 percent of villages (NCERT, 1992, p. 42) In spite of this success, India faces significant challenges in attendance, retention, and dropout rates: about 20 percent of children enrolled do not attend school regularly and about 40 percent of those who enroll drop out before completing the primary cycle. When accounting for gender, caste, and class, the disparity is more alarming (p.94). Hence, the idea of quality centeredness in education gained serious momentum, raising to the limelight several concerns, one being that of production and distribution of educational content (p.133). According to the World Bank India education sector reports $(1996$; 2001), textbooks reputed to be of poor physical quality and readability, are often the sole available reading material for most students. Around the same time, there has been international pressure to make educational content more engaging and relevant to the local populace for creating better-prepared future citizens (OECD, 2001). This raises key challenges in the Indian education arena, with a focus on reducing the gap in education outcomes across states and among groups through meaningful content.

Meantime, the reputation of India as the IT hub has energized some of the state governments, especially in the South of India, to promise e-literacy to its people by 2015 (Biswas, 2004). This is being done to reduce the digital divide as well as to adhere to the Education For All campaign (EFA) initiated at the World education conference at Jomtien in 1990. Given that more than half of India's population have access to television, this medium has been looked at seriously to fulfill this promise (Sharma, 2000; Phalachandra, 1998; Egan et. al., 1993). However, in recent years, there has been a visible policy shift towards computer-enabled 
education programming in primary and secondary schools across the nation (UNESCO, 2003). Unfortunately, according to recent World Development indicators, less than $2 \%$ of the Indian population currently has access to the internet, the majority being in the urban area. This has posed as a serious stumbling block in the ambitious scaling of e-literacy through computers across states. It has propelled governments, international think-tanks and the private sector alike to seek for innovative means of content creation and distribution to best capitalize on these cost intensive resources within disenfranchised settings.

\section{Language, education and technology}

A language is something infinitely greater than grammar and philosophy. It is the poetic testament of the genius of a race and a culture and the living embodiment of the thoughts and fancies that have molded them. -Nehru

The people of India are in general multilingual. They speak many languages and dialects, which are mostly varieties of about 15 principal languages and at least a thousand dialects (Pattanayak, 1991). However, the practices in publishing are contrary to the declared three-language formula' policy goals in schools (Ghosh \& Zachariah, 1987) to foster a multilinguistic nation. For example, the national children's book trust publishes more books in English than in Hindi or other local dialects. Currently, $50 \%$ of all literature published nationally is in English while the other half covers the main Indian languages (p. 27). Given the dearth of content in regional and local languages, the Indian government, non-profits and the private sector have been looking at innovative and alternative means in overcoming this barrier. Several efforts have spawned over the last few years to capitalize on government momentum in technology and education in view of reducing the digital divide. However, ICT content catering to social and cultural 
empowerment through karaoke entertainment as provided by the SLS folksongs project is unprecedented.

\section{Same Language Subtitling, literacy and socio-cultural impact}

The Same Language Subtitling (SLS) concept for literacy was initially conceived in 1996 by Dr.

Brij Kothari, founder of PlanetRead, the non-profit agency executing SIS and professor at the Indian Institute of Management in Ahmedabad, India (IIM-A). The SLS feature entailed leveraging popular film-based entertainment programming on television with subtitles in the same language to enhance reading experiences among the vast neo-literate ${ }^{1}$ majority in India. The subtitles change color to match the audio track exactly so that even a non-literate person is able to identify the word being sung at any given time. Almost ten years later, the enormous benefit of this simple and low cost literacy initiative has become a recognized phenomenon through accumulated empirical evidence over the years (Kothari, 2000; 2004). The formal evaluation of SLS and reading skills started in 1998 with a controlled experiment using subtitled Hindi film songs recorded from Chitrahaar, a song program on television in a Gujarati medium government school in Ahmedabad. Within a short span of time, it was evident that SLS of film songs did contribute to reading improvement (Kothari \& Takeda, 2000, p.136). Following this, in an effort to scale this literacy success and capitalize on the high media penetration in rural areas ${ }^{2}$, SLS has been utilized for song-based programming by Doordharshan, the public broadcast television, in the states of Gujarat, Maharashtra, and Andhra Pradesh and on the national network targeting all Hindi speaking states since 2002.

\footnotetext{
${ }^{1}$ Neo-literates refer to newly literate people. This populace are at the risk of relapsing into non-literacy if literacy practice is not sustained.

${ }^{2}$ The National Readership Survey conducted in 2002 estimates that about 383.6 million people have direct access to television in 81.6 million homes; 500 million in total to indirect access to televisions through their neighbors. The total population of India is almost a billion.
} 
In the last few years, the correlation of SLS with reading improvements and audience preference of subtitled to unsubtitled songs has been established time and again (Kothari, 2000; Kothari \& Takeda, 2000; Kothari, Pandey, \& Chudgar, 2004). Furthermore, the role of SLS in enhancing entertainment has been demonstrated with literacy being achieved subliminally (Kothari \& Takeda, 2000, p. 135). However, amidst this success has emerged reservations on using film-based content for education: The battle against 'filmi culture' on moral grounds has proven to be a major stumbling block for some policy makers (p. 137). In 2001, an agreement was made between Doordharshan, the national television station and the Indian Institute of Management in Ahmedabad (IIM-A) to try SLS on folk song programming recorded in-house. Results showed that even though film song programs gained a higher viewership than folk song programs, and with film songs of higher recording quality than folk, the folk song lyrics became more widely used and displayed openly by people in schools and homes. In fact, with little publicity, this folksong project raised about 50\% of the telecast and SLS expenses from advertising revenue (p. 136). This positive outcome gave birth to the Stills in Sync project, the creation of a novel literacy and socio-cultural digital jukebox of popular folksongs using SLS.

\section{ICT project in rural India}

\section{Kuppam}

Located at the confluence of Karnataka, Tamil Nadu and Andhra Pradesh, Kuppam is strategically if not symbolically stationed amidst the three states. The constituency of former chief minister Chandrababu Naidu, Kuppam had the reputation of a prison encampment area as of ten years ago. Today, Kuppam is brandished by some as the 'silicon valley of the east' (Srinivasan, 2001, p. 3) where new technologies are being tried and tested within its vicinity. It is 
a rural Indian village, 105 kilometers from Bangalore on the Bangalore-Chennai railway. Telugu is the official and most widely spoken language in the state. Yet, given its proximity to the neighboring states and a sizable Muslim population, Tamil, Kannada Urdu and Hindi are spoken too. With a population of around 300,000 people across 5 districts or mandals, the area has experienced a transformation in health, education, agriculture and employment services. According to the local district statistics (KADA, 2003), impressive strides in the education setting have been made. Literacy rates are reported to have jumped from $26 \%$ in 1989 to $68 \%$ in 2003 (Table 1). Within those years, dropout rates decreased by almost $84 \%$. The number of primary and secondary schools almost tripled in number to a point where there is no habitat reported to currently have no schools within walking distance (Table 1). The government statistics on access to schooling rivals statistics in learning achievement. Passing rates amongst 7th and 10th grades have swung from a low of 36\%-48\% respectively in 1989 to an applaudable 94\%-99\% in 2003. In 2003, the Kuppam district committed to installing 20 public high schools with computers under the Vidhya Vahini Scheme as an attempt to reduce the digital divide with the goal of covering all 53 schools by end 2005. Further reforms included the establishment of a model residential school with the support of World Bank in 2003, targeting girls from the most

marginalized scheduled castes and tribes (Table 1).. The Dravidian University, a public institute of higher learning was set up in 2003 to focus on South Indian folklore and culture. The SLS folksongs project was launched within this transformative flux.

\section{Product description}

Through the sponsorship of Hewlett-Packard, PlanetRead, the acting non profit has created an Internet/CD-based jukebox of SLS songs using local popular folksongs with social awareness 
themes such as child labor, education, farmers plight, women's empowerment, dowry, HIVAIDs and caste segregation. By using photographic stills of the local village environment, and combining it with folksong audio files and subtitles, this product is a relatively inexpensive means targeted towards cultural regeneration, value-based education and incidental literacy through entertainment. Consumers view and sing along with the songs and are able to print/download transcribed lyrics in the script of their choice. This is meant to enhance literacy rates of neo-literates, and build participation through the ICT usage of content that is contextual, relevant and local. Popular folksongs performed by respected local singers has been recorded professionally. Each song has been picturized in the artist's village context through a set of digital photos. Music-Stills show the photos against the song, with the lyrics appearing as SLS. As the song is being sung, the appropriate text gets highlighted at the bottom of the screen. Much like karaoke, the ability to turn on/off the vocals leaving just the acoustics have been provided for those familiar with the song.

\section{Production of content}

PlanetRead is the non-profit agency that conceptualized and implemented the SLS folksongs project. At the start of the project, a survey was conducted to gauge local preferences on the most popular folksongs and folksingers in the Kuppam constituency. The survey was structured to gain a consensus across age groups, gender and village settings. Additionally, it included the transcribing of lyrics of favorite folksongs in these areas. Simultaneously, the team created a trial DVD/CD by taking a random sampling of folksongs supplemented with photographs of the villages and the SLS feature provided. The main goal here was to ascertain the resources needed, human, physical and financial, in the making of this product. That said, in viewing this 
prototype, several concerns came to the surface that allowed the team to re-strategize the content creation process.

\section{Audio}

The prototype DVD/CD was a compilation of 8 songs, most being popular Hindu ${ }^{3}$ devotional songs. Even the non-religious songs based on agriculture or love themes evoked the names of Hindu gods and goddesses. Furthermore, the themes seemed more geared towards adults than children. The average song was about 5 minutes long and the visuals were literal, repetitive and lacking in variability. The acoustics was high pitched, accompanied by a single local instrument. Most of the singers sang at a fast pace which in turn made the subtitles difficult to follow. Several of these features, even though apparently technical in nature, had its roots in deeper issues that needed to be resolved.

\section{The Dilemma of Authenticity}

Every year famous local folksingers at a nearby village perform folk theatre. Its an all night affair. This performance is attended mainly by the men. However, there is a separate performance early morning where these artists conduct storytelling sessions for the women and children. This event is attended by thousands of villagers on a regular annual basis. In spite of this high attendance, there is a concern on the fading of the folksong tradition amongst these folksingers. A septuagenarian folksinger from this village lamented, "Young people no longer care... they want to make money, listen to film songs and have no time for us." He claimed that the folk tradition was going to end with his peer troupe. However, he did give credit to the former government for supporting the folk arts. Besides government support, what needs to be

\footnotetext{
${ }^{3}$ Hindu religion is the dominant religion in India. Around $80 \%$ are Hindus while around $12 \%$ are Muslims belonging to the Islamic faith. The other $8 \%$ of the population are followers of Christianity, Buddhism, Sikhism, Judaism, Zoroastrianism or Jainism.
} 
noted is that a good portion of the actual performance costs often came from villagers themselves who pooled their own money to support this cultural pursuit. Over the months, it was discovered that authentic Andhra folk music is in actuality long narratives and ballads that go on for hours if not days. Also, even though many of the folksongs the team was exposed to were devotional in nature, historically these ballads, known in the local parlance as Jaanapada geethaalu, are basically pastoral or romantic in nature (INF, 2001). Furthermore, folk musicians often use just the dирри, the local drum-like instrument with few other accompaniments. While there is an evident presence of folk across villages, Tollywood music or Telugu cinema music is also highly popular in these regions, rural and urban alike. The challenge thereby was to create a product that was sensitized to local tastes yet had the potential to scale across board.

\section{Limitation of folksong survey}

The folksong survey was useful to the extent of leading the team towards the most popular songs across villages, primarily that of devotional songs. However, few songs recorded in our surveys were appropriate for children and fewer geared towards current social issues. Given that much of the content was Hindu centric, there was a need to seek for songs that also appealed to minority groups in villages. Also, there was a conscious decision on the teams part to select gender biased songs with the intention of enhancing usage of high end technologies by girls and women through

pertinent and engaging content. In essence, the search was on for a hybrid between traditional folksong music and maverick social awareness themes. Given the time constraint, and exigent needs, the most effective plan was to seek out for existing efforts among the local community.

\section{Local Resources}


From a typical rural setting, Kuppam metamorphosized into a haven of local activism. On scratching the surface, an entire web of actors were revealed through the appropriation of the local social capital. ${ }^{4}$ There were nine active non-profits and one Church based organization that was dedicated to social and cultural regeneration within the community. They catered to a wide array of issues from water sanitation, agriculture, HIV/AIDS, herbal medicine to community development. Most of these organizations were 15-20 years old if not older and had strong ties with the local village council. Some had links with International donor agencies. In particular, the local self help women groups ${ }^{5}$ played an instrumental role in the project from garnering the right contacts for data collection, serving as links to folk artists and activists to providing feedback on the product. Another important linkage was with the Poor People Education and Development Society organization (PPEDS), ${ }^{6}$ a non profit organization that used street theatre and folksongs to

\footnotetext{
${ }^{4}$ OECD definition of social capital is the "networks, together with shared norms, values and understandings which facilitate cooperation within or among groups.' In this project, the team had appropriated P.S Jayamma's social network to further the production of the ICT content. Having won the social worker award in 2003 for her fifteen years of service, P. S. Jayamma was an invaluable and critical part of this content generating process.

${ }^{5}$ Arguably one of the most successful development practices, SHGs are a savings-led, women-centered initiative in microfinance that has revolutionized banking practices among the poor (NABARD, 2002). The SHG centers in Kuppam and its neighboring villages are impressive in its expanse and organizational sophistication particularly because this is a relatively nascent development phenomenon. Starting with micro credit to poor entrepreneurial women, these SHGs had gone onto becoming portals of values, mores, and awareness campaigns for health, education and welfare as evinced by the centers activities. In the Kuppam constituency itself, SHGs had grown from a mere 159 in 1994 to about 3000 women groups in 2003 (Table 2). Parallel to this, their dependence on money lenders has reduced dramatically. While more than $70 \%$ of the women groups were dependant on local money lenders in 1989, in 2003 the dependence had reduced to a mere 3\% (Table 2). The SHGs served as one of the most important mediums of content production providing supportive networks, linkages to folk artists and acted as a hub for generating strong relevant themes that concerned the community at large.
}

${ }^{6}$ Founded in 1988 by Dr. James Yen from the Philippines under the larger umbrella organization, the International Institute of Rural Reconstruction, this organization focused on HIV-AIDS, women empowerment, micro-credit and agricultural development. A few years ago, they had weaned themselves for the most part from its international parent and became an independent entity, managed and run by local activists. Four years ago, they initiated the Culture Action wing. The credo for PPEDS is as follows: Go to the people, Live among them, Learn from them, Plan with them, Start with what they know, Build on what they have, Teach by showing, Learn by doing, Not a showcase but a pattern, Not odds and ends but a system, Not piecemeal but an integrated approach, Not to conform but to transform, Not relief but release! 
promote awareness on social issues across villages in different districts. In the interview with the director of PPEDS and a local musician, it became apparent that folksongs was a powerful means of evoking change within village settings. He spoke of their efforts at integrating sensitive topics like HIV/AIDs into their folksongs which seemed to gain an acceptance amongst the villagers. However, he did draw attention to the processes in contextualizing content across varied village settings. He stated that dialects and instrumental beats varied from village to village, making usage of folksongs more of a challenge. Furthermore, different castes had different songs which were in itself exclusive domains. Also, he went on to extrapolate the complexity of folksong usage by stating the 'light' nature of awareness songs which used simple beats to the more intense folk music which used the heavier drum beats. When asked if the villagers preferred folk to cinema songs, he stated that they mainly listened to folk. However, he did clarify that among the youth, Telugu cinema songs were gaining in popularity. Hence, for every performance, their Culture Action group would include one or two songs that was more in the cinema style. As for recording, he remarked that folk singers found it difficult to sing with non folk instruments such as the harmonium as they were used to only the $d u p p u$, the local instrument. These were useful lessons that helped shape the production process even further.

\section{Finalizing folksongs}

It was apparent through this fieldwork that the concept of "community" was not a homogenous entity: one caste had their own set of songs, one village had their own style and instrumental 
preference while another had their own favored dialect which differed from the rest. Hence, more emphasis needed to be made on commonalities once the differences had become transparent. The redefinition of the terms "relevance," "participation," and "quality," made it easier to proceed in the production and recording of the CD. "Relevance" was defined as content that was not caste or religion specific but rather theme-based. Issues such as women's empowerment, farmers plight, health issues, domestic violence and education was harnessed, themes that crossed all boundaries yet remained faithful to the environment served. "Participation" was measured by the degree of enjoyment of folksongs among a diverse set of groups spanning across villages, gender, caste, class, age and other traditional group categories. And "quality" was interpreted as the key element that allows transferability across groups. The assumption was made that if the content had strong visual, acoustic material and emotional resonance, it would be more likely embraced across board. Folksongs had to be of a high caliber, in terms of recording, instrumentals, and vocals to sustain engagement. Based on these measures, and with the aid of SHGs, PPEDS and local popular folk artists, twelve folksongs were chosen. The array of themes are as follows: environment, savings, women solidarity, child marriage, hunger, dowry, alcoholism, extreme poverty, and love songs. The decision to use a Hindu devotional song was made in spite of the initial team resistance to religious bias given its enormous popularity across village settings. These songs had the following features in common: simple vernacular language, slow pace to allow for easier readability of the subtitles and stanza repetition that would facilitate learning through familiarity. Also, most of these songs were in story form which kept with the authenticity of the ballad nature of folksongs. After some rigorous auditioning, the singers were chosen, particularly based on their ability for tonal variation and flexibility to sing with different groups. Also, two child artists were chosen for the recording to increase engagement among children and provide variation within the song itself. 
The songs were within a 2-3 minute time frame, more in style with the cinema length of songs. Non-folk instruments such as the flute and harmonium was used for some songs to create cinema appeal. Some songs with "heavier messages" such as bride burning, dowry and poverty were accompanied with heavy beats from the $d u p p u$ while the "lighter" environmental and love songs were accompanied by the flute, and the harmonium. To overcome the obstacle of recording the folksingers with instruments unfamiliar to them, the vocals were recorded separately from the instrumentals. In the end, the prime benchmark was that of cinematic recording quality with the soul and meaning of folk. As for the subtitling, given that most televisions and computers in villages were old models and had substantially curved screens, the text had to be placed a few inches higher from the bottom of the screen for easier viewing.

\section{Transcribing folksong lyrics visually}

Each song needed about 30-40 stills that would simultaneously be shown along with the audio file. The photographs needed to be literal representations of the lyrics at hand to maximize learning through audio-visual linkages. The decision was made to stay away from abstract imagery for this very purpose. To encourage localism, the imagery was mostly drawn from neighboring villages. To increase buy-in, locals were chosen instead of professionals to act out entire scenes of the folksongs. Our main challenge though in visualizing was not so much the artistic aspect but rather the process of engaging the locals to pose for the photographs. The main dilemma was in designing an incentive system for the local actor's time and hard work. Locals were remunerated based on their time and effort in posing for the songs. However, questions on how much to pay a child versus an adult came to play. It is important to note here that most locals did not ask for any compensation. There was some opposition to these remuneration methods 
from the local church. One of the priests accused the team of creating an unhealthy relationship between social work and monetary gains. He believed that by providing monetary incentives, it would create a dysfunctional attitude towards local participation and community development. After struggling with this issue, the decision was made to continue paying villagers based on their time and effort. The rationale for this was primarily that this project was too abstract for the villagers to conceive as an immediate benefit to their lives. However, this issue of linking social work with monetary gain should be investigated further by development agencies, governments and think-tanks when embarking on projects where local existing non profits efforts are in place.

\section{Discussion}

To best understand the potential of the SLS folksongs product, we should look at the affordances that each of its components have and its aggregate impact when brought together in a meaningful manner. As stated above, the impact of the SLS feature on literacy gains has already been established (Kothari, 2000; Kothari \& Takeda, 2000; Kothari, Pandey, \& Chudgar, 2004). Also, its effect on entertainment has been substantiated through audience preference of the SLS feature versus non SLS feature (Kothari, 2000). However, with the Stills in Sync SLS folksongs karaoke product, perhaps the most unique feature is in its capacity to create social and cultural change within disenfranchised settings.

In fact, in reviewing karaoke as an electronic communications technology and cultural practice as expounded in Casey Man Kong Lum's "In Search of a Voice: Karaoke and the Construction of Identity in Chinese America," Zheng (1998) outlines for us the social implications of karaoke. Zheng suggests that the karaoke audience are not merely media text readers. Karaoke production and consumption is interactive and participatory where people "can 
and do act as active agents in indigenizing or localizing existing mass media products" (p. 77). In doing so, Zheng (1998) states, social bonding and community strengthening is established. This practice, the author argues, can be particularly useful for economically deprived communities. Furthermore, Adams (1996) exclaims that through the indigenization of songs, people can claim their cultural, social, regional differences and identities in karaoke spaces. The public nature of karaoke interaction in particular lends itself well to socialization of groups and individuals. According to Adams (1996), karaoke is an experience of scripted simulation for groups (p. 515). In other words, a set of multicultural and transnational mechanisms scripted by the pertinent group and internalized by its members in performance create and reinforce their group identities. Hence, the SLS folksongs content is unique in its ability to provide the social cohesiveness through karaoke amongst disadvantaged international settings while propelling mass literacy through entertainment.

The actual indigenous content is however the folksongs that have been digitalized for empowerment within disadvantaged groups. Due to the high popularity of film songs in India, in both rural and urban regions alike, it is valid to speculate on the pertinence of digitalizing folksongs in this project. Given the challenges in the production process as outlined above, the question of validity is key to the future of this product. Questions abound: Are folksongs still being enjoyed by the majority populace? What themes do these folksongs address? Is folk largely a rural phenomenon? Is folk primarily static and historic or does it change with time? Is the revival and preservation of folksongs driven by Orientalists indulging in rural romanticism? An in-depth scholarship of folk in socialization and activism is a topic that is beyond the scope of this paper. However, it is important to briefly touch upon some of these issues to aid in the understanding of the choice of folksongs for empowerment. 
Trilling (1971) and Narayan (1993) argue that folk has been largely perceived as that which is bucolic, bounded, and unchanging. Some folklorists have amassed compelling evidence to construe "folk" as a more three-dimensional, non-homogenous and dynamic entity where folksongs do in fact respond to the current social and cultural milieu (Appadurai, 1991; Narayan, 1993; Manual, 1998). However, this has been ignored by several scholars as it is commonly believed that it does not fit the western paradigm of "self-contained peasant authenticity where references to changing realities as adulterations are edited out" (Narayan, 1993, p. 177). Even the regionalization of folksongs seem to have been artificially encased by governments, scholars and publishers in seeking for categorization and clean cut boundaries (Trilling, 1971). Furthermore, Naithani (1996) writes compellingly about the politicization of folk across centuries, tracing the historical roots of folk to the modern times. She argues that folk has been an expression of class consciousness over these centuries (p. 74). She draws on examples of British Indologists and Orientalists that chose to freeze folklore and folksong as an antiquarian expression of past cultures, that which needed to be preserved. In contrast, she outlines the current trends of folk being used for political and social activism. For example, she states that Gaddhar, a Marxist and folk activist as part of the Peoples War Group (PWG) in Andhra Pradesh, moves from village to village singing folksongs on oppression and inequity among the rural populace (p. 78). His high popularity among the villagers has driven the Andhra police today to put a bounty on his head (p. 78). However, she reminds us that folksongs can also be used as a tool servicing a government agenda (p. 78). Narayan (1993) asserts that there has been several pro-social efforts by the government in using folksongs to influence behavior in health, education, sanitation and other social issues over the years, asserting their power to shape people's thinking and behavior. 
Hence, with a potent combination of emotional appeal, intrinsic enjoyment and social impact, folksongs can serve as a useful tool for literacy and overall engagement.

Furthermore, it has been found that when mass media are directed towards particular issues such as documented examples of contraception in Pakistan, India, and Bangladesh, family planning in Kenya and female condoms in Tanzania, significant and impressive results in behavior change has been seen amongst disadvantaged marginalized groups (Olenick, 2000, p 48). Lent (1980) argues that folk media is in fact a better means of carrying messages than artificially construed social themes often structured by governments in the effort of mass empowerment (p. 87). He reasons that folk media often employ symbols that are readily comprehensible and accessible to the village populace. This underlines the truism that popular media often does not cater to the majority populace as in the case of India where around $70 \%$ of the population live in villages and yet urban values pervade Indian media (Ahmed, 1992, p 294). Lent (1980) does emphasize that folk media can serve as a counter force to the constant stream of urban media to rural domains, thereby affirming disadvantaged communities (p. 79). Ginsburg (1991) agrees, stating that “...indigenous media offers a possible means- social, cultural and political for reproducing and transforming cultural identity among people" (p. 92).

The use of folk music in itself allows for further empowerment. According to Lewis (1982), music in itself is an ordered system of meanings and symbols in terms of which social interaction takes place (p. 185). The author draws parallels between music and social structure wherein music does not merely reflect the social structure but creates it. Music is therefore a framework of beliefs, expressive symbols and values in terms of which individuals define their world, express their feelings, and make their judgment. Hence, when we view the SLS folksongs product in its entirety, there is the potential to address wide empowerment dynamics through 
social and cultural regeneration and affirmation as well as literacy gains through the "first world" tools of karaoke.

\section{Conclusion}

There is enormous scope in taking this product in many different creative directions. Given that many of these are ballad songs, the next step could be the SLS folk story book model. Audiences can range from villagers, migrant urban workers to the growing global diaspora keen on holding and shaping their native cultures and languages. Animation is definitely a desirable option in visualization, catering to children as well as being cost effective. Puppetry can be used in the format of stop-motion animation, thereby opening the path to digitalizing non-profit puppetry group efforts engaged in social activism. Furthermore, given the high popularity of devotional songs, there is a need to shelve reservations and personal biases towards religious content. Creating a DVD/CD of different religious songs would be a powerful means of engagement, especially targeting adult literacy. Additionally, one can move a step further in the participation process where material can be completely designed by the consumers themselves. Children can write their own stories, design their own animation, adults can do their own composition of lyrics and local villagers can be the photographers. These exercises could be incorporated into the school curriculum where meta-cognitive abilities of children and adults alike would come to play. However, production is only one side of the story. We need to explore all channels of distribution, from government to the private sector alike if we are to create a sustainable and effective means of enhancing literacy through this novel social and cultural approach. Overall, we need to consider diverse expressions through diverse means if we are to truly engage a diverse populace. 


\section{Acknowledgement:}

The production of the SLS folksongs project has been a team effort. I would like to thank Planetread's Kuppam team: P.S Jayamma, Amit Dixit, Maya Sukumar, Nirav Shah, K.T. Pauly, and Ashok Joshi. I am particularly grateful to Dr. Brij Kothari for his mentorship and support. I would also like to pay tribute to the local Kuppam government office that provided easy access to Kuppam's education and development data. Last, but not least, I would like to emphasize P.S Jayamma's invaluable role in this project. Due to her drive, local credibility and dedication, we were able to take this project to a much higher footing. Her efforts in this project have been deeply felt. 


\section{$\underline{\text { Tables }}$}

\begin{tabular}{|c|c|c|c|c|}
\hline & 1989 & 1994 & 2003 & $\%$ increase/decrease \\
\hline Population & & 265922 & 317208 & \\
\hline Literacy Rate & $26.40 \%$ & $30.66 \%$ & $68.49 \%$ & $159.43 \%$ \\
\hline School Age Children & 27269 & 31769 & 73242 & $168.59 \%$ \\
\hline School going children & 16088 & 20332 & 71434 & $344.02 \%$ \\
\hline Drop outs & 11181 & 11437 & 1828 & $-83.65 \%$ \\
\hline \%age of enrolled & $59 \%$ & $64 \%$ & $97.53 \%$ & $65.31 \%$ \\
\hline Teachers & 311 & 396 & 1490 & $379.10 \%$ \\
\hline Teacher-pupil ratio & $1: 51$ & $1: 55$ & $1: 48$ & \\
\hline Class room: Pupil ratio & $1: 70$ & $1: 68$ & $1: 60$ & \\
\hline Total Primary Schools & 207 & 235 & 436 & $111 \%$ \\
\hline Total UPP Schools & 18 & 27 & 74 & $311 \%$ \\
\hline Total high Schools & 9 & 14 & 53 & $489 \%$ \\
\hline Junior colleges & 1 & 1 & 6 & $500 \%$ \\
\hline Total degree colleges & 0 & 0 & 6 & $600 \%$ \\
\hline Habitation having primary/UP schools & 207 & 235 & 510 & $146 \%$ \\
\hline School less habitations (beyond $1 \mathrm{~km}$ ) & 204 & 176 & 1 & \\
\hline 10th Grade passing results & $36 \%$ & $43.70 \%$ & $94.20 \%$ & \\
\hline 7th grade passing results & $48 \%$ & $54 \%$ & $99.56 \%$ & \\
\hline Computerization in Schools & . & & 20 & \\
\hline $\begin{array}{l}\text { Access to print-total circulation of } \\
\text { newspapers }\end{array}$ & 163 & 518 & 4325 & \\
\hline
\end{tabular}

Table 2: Kuppam Constituency Self Help Group Statistics (KADA 2003)

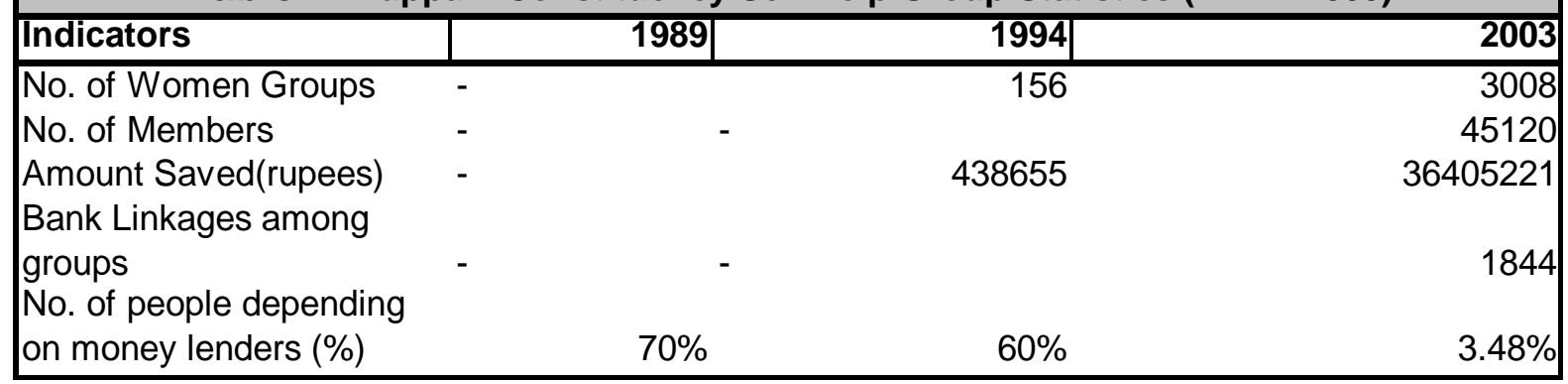

\section{Abbreviations}

$\begin{array}{ll}\text { AIDS } & \text { Acquired immune deficiency syndrome } \\ \text { CD-ROM } & \text { Compact Disc } \\ \text { CEO } & \text { Chief Executive } \\ \text { CIC } & \text { Community Information Centers } \\ \text { CIIL } & \text { Center Institute of Indian Languages } \\ \text { CPU } & \text { Central Processing Unit } \\ \text { DD } & \text { Doordharshan }\end{array}$




$\begin{array}{ll}\text { DVD } & \text { Digital Video Disk } \\ \text { EDC } & \text { Education Development Center } \\ \text { EFA } & \text { Education For All } \\ \text { ICT } & \text { Information and Communication Technologies } \\ \text { IIM-A } & \text { Indian Institute of Management -Ahmedabad } \\ \text { KADA } & \text { Kuppam Area Development Authority } \\ \text { HIV } & \text { Human Immunodeficiency Virus } \\ \text { HP } & \text { Hewlett Packard } \\ \text { INF } & \text { India Network Foundation } \\ \text { NABARD } & \text { National Bank for Agriculture and Rural Development } \\ \text { NCERT } & \text { National Council of Educational Research and Training } \\ \text { OECD } & \text { Organization for Economic Cooperation and Development } \\ \text { PC } & \text { Personal Computer } \\ \text { PISA } & \text { Program for International Student Assessment } \\ \text { PPEDS } & \text { Poor People Education and Development Society } \\ \text { PPP } & \text { Private Public Partnerships } \\ \text { PROBE } & \text { Public Report on Basic Education in India } \\ \text { PWG } & \text { Peoples War Group } \\ \text { SHG } & \text { Self Help Groups } \\ \text { SIS } & \text { Stills in Sync } \\ \text { SLS } & \text { Same Language Subtitling } \\ \text { UNESCO } & \text { United Nations Educational, Scientific and Cultural Organization } \\ \text { ZP } & \text { Zilla Parishad } \\ & \end{array}$

\section{References}

Adams, V. (1996). Karaoke as modern Lhasa, Tibet: Western encounters with cultural politics. Cultural Anthropology, 11 (4), 510-546.

Ahmed, S., A. (1992). Bombay films: The cinema as Metaphor for Indian society and politics. Modern Asia Studies, 26 (2), 289-320.

Annamalai, E. (1981). Language movements in India. New Delhi: Center Institute of Indian Languages.

Appadurai, A. (1991). In gender, genre and power in South Asian expressive traditions. Philadelphia: University of Pennsylvania press.

August, D., \& Hakuta, K. (1998). Educating language-minority children. Washington, DC. National Academy Press.

Biswas, S. (2004, May 13). How India's elections were won and lost. Retrieved October 29, 2005, from BBC World News, South Asia Web site: http://news.bbc.co.uk/2/hi/south_asia/3711395.stm

Egan, M.W., Sebastian, J., Welch, M., Page, B., Nkabinde, Z., \& Jones, D. (1993). Quality television instruction; perceptions of instructors. Education Journal, 7, 1-8. 
Ginsburg, F. (1991). Indigenous media: Faustian contract or global village? Cultural Anthropology, 6(1), 92-112.

Ghosh, R., \& Zachariah, M. (1987). Education and process of change. London: Sage Publications.

CSCS. (2001). Folk performing arts of Andhra Pradesh. Retrieved on October 29, 2005, from Government of Andhra Pradesh Web site:

http://www.cscsarchive.org:8081/MediaArchive/Library.nsf/0/755D6C94F8956B6D652568E40 $\underline{\text { 01D375E? OpenDocument } \& \text { Start }=1 \& \text { Count }=1000 \& \text { ExpandView } \& \text { StartKey }=\text { Folk }}$

Kothari, B., Pandey, A., \& Chudgar, A. (2004). Reading out of the idiot box: Same language subtitling on television in India. International Technologies and International Development. $1(3), 23-44$.

Kothari, B., \& Takeda, J. (2000). Same language subtitling for literacy: Small change for colossal gains. In S. Bhatnagar., \& R. Schware (Eds.) Information and Communication Technology in Development (pp 176 - 186).World Bank Institute, New Delhi: Sage Publications.

Kothari, B. (2000). Same language subtitling on Indian television: Harnessing the power of popular culture for literacy. In K. Wilkins (Ed.), Redeveloping communication for social change: Theory, practice and power (pp 135-146). New York: Rowman \& Littlefield.

Lent, A., J. (1980). Grassroots renaissance; folk media in third world nations. Folklore, 91 (1), 78- 91.

Lewis, G.H. (1982). Popular music: Symbolic resource and transformer of meaning in society. International Review of the Aesthetics and Sociology of Music, 13 (2), 183 -189.

Manuel, P.(1998). Music, identity, and images of India in the Indo-Caribbean diaspora. Asian Music, 29 (1), 17-35.

Mills, C., W.(1963). Power, politics and people. New York: Oxford University Press.

NABARD (2002). Linking banks and self help groups in India: An assessment. New Delhi.

Naithani, S. (1996). Political ideology and modernization of folklore: A study of three contemporary Indian artists, Jahrbuch für Volksliedforschung journal.

Narayan, K. (1993). Banana republics and V. I. degrees: Rethinking Indian folklore in a postcolonial world. Asian Folklore Studies, 52 (1), 177-204.

OECD. (2001). Knowledge and skills for Life: First Results from PISA 2000. 
Olenick, I. (2000). Women's exposure to mass media is linked to attitudes toward contraception in Pakistan, India and Bangladesh. International Family Planning Perspectives, 26(1), 48-50.

Pattanayak, D. P. (1991). Language, education, and culture. New Delhi: Central Institute of Indian Languages.

Phalachandra, B. (1998) Training of teachers using interactive video technology. India: National Council of Educational Research and Training.

Sharma, S (2000). Interactive distance education for in-service teachers in India. Educational Media International, 37(1), 68-72,

Siddiqui, A., \& Haque, Z.. (1964). Folklore research in East Pakistan. Asian Folklore Studies, 23 (2), 1-14.

Trilling, L. (1971). Sincerity and authenticity. Cambridge: Harvard University Press.

UNESCO (2003). IT in education innovation for development: Interfacing global and indigenous knowledge. Bangkok.

Varshney, A. (1995). Democracy, development and the countryside: Urban-rural struggles in India. New York: Cambridge University Press.

World Bank (1996). Primary education achievement and challenges (Report no.15756- IN). Washington DC: Author.

World Bank. (2001). India: Expanding and improving upper primary education in India. (Report no. 20347 -IN). Washington DC: Author.

World Business Council for Sustainable Development. (2005) HP e-inclusion, Kuppam hpicommunity, Casestudy2005. Retrieved on October 29, 2005, from Hewlett Packard Web site. http://www.wbcsd.org/plugins/DocSearch/details.asp?type=DocDet\&ObjectId=MTQ0ODc

Zheng, S. (1998). Review author[s]: Of Casey Man Kong Lum's In search of a voice: Karaoke and the construction of identity in Chinese America. Asian Music, 30(1), 185-190.

Word Count: 6026

Pages: 23

Date: January 26, 2006 